\title{
Has Contemporary Academia Outgrown the Carl Sagan Effect?
}

\author{
(1)Susana Martinez-Conde \\ State University of New York (SUNY) Downstate Medical Center, Brooklyn, New York 11203
}

In 1991, the American astronomer and superstar science popularizer Carl Sagan was nominated for membership in the National Academy of Sciences. Despite the efforts of some strong backers-including the Nobel laureate Stanley Miller, who advocated passionately for Sagan's admission to the Academy-the nomination did not succeed. Sagan was blackballed in the first round of voting, which led to a full debate and vote by the Academy members. He then secured $<50 \%$ of "yes" votes in the final round, far from the two-thirds required for admission to the Academy. Sagan's biographers have argued that the Academy's rejection of Sagan, and Harvard's prior denial of his tenure, were the direct consequence of the phenomenon that has become known as the "Sagan Effect": the perception that popular, visible scientists are worse academics than those scientists who do not engage in public discourse. Yet, later analyses of Sagan's output have indicated that his academic contributions compared favorably to those of other Academy members (Davidson, 1999; Poundstone and

Received Jan. 8, 2016; revised Jan. 12, 2016; accepted Jan. 13, 2016.

This work was supported by a challenge grant from Research to Prevent Blindness Inc. to the Department of Ophthalmology at SUNY Downstate, and by an Empire Innovation Award from The State of New York. I thank the Society for Neuroscience for selecting me as recipient of the 2014 Science Educator Award, and for inviting me to write this commentary. I am indebted to Stephen L. Macknik for his detailed feedback and extended discussions on the topic of this article. I also thank Robert Alexander for discussion and Mahzarin Banaji for her thoughts on the framing of this article. Jordi Chanovas Colomé, Max Dorman, Manuel Ledo, and Rosario Malpica contributed research and administrative support, and very helpful input. Devin Powell provided invaluable assistance in compiling the sample of neuroscientists surveyed, and conducting and transcribing the interviews themselves. I am most grateful to all the scientists that agreed to the interviews for their time and candid reports.

The author declares no competing financial interests.

Correspondence should be addressed to Susana Martinez-Conde, Department of Ophthalmology, SUNY Downstate Medical Center, 450 Clarkson Ave., Brooklyn, NY 11203. E-mail: smart@neuralcorrelate.com.

DOI:10.1523/JNEUROSCI.0086-16.2016

Copyright $\odot 2016$ the authors $\quad 0270-6474 / 16 / 362077-06 \$ 15.00 / 0$
Chyba, 1999; Shermer, 1999; Morrison, 2006; Jensen et al., 2008).

Fast forward to 2011. Sean Carroll, a nontenure track research professor at Caltech-and science writer-wrote a widely read blog post, facetiously entitled "How To Get Tenure at a Major Research University," drawing partially from his own previous failed tenure attempt at the University of Chicago (Carroll, 2011). He offered 13 pieces of advice, approximately half of which are straightforward, even self-evident: "Do good research; Make an impact in the field; Bring in grant money." Others are, to a large degree, counterintuitive: "Don't be too well known outside the field; Don't write a book; Choose your hobbies wisely." Carroll argued that academics look askance at colleagues that have too high of a public profile. Not out of envy-but because they worry that public scientists care more about their media presence than about discovery. Likewise, authors of popular science books face concerns that they have wasted time that should have been dedicated to doing research. Carroll's most radical warning is that extracurricular pastimes should have zero resemblance to academic work. It's OK to fly planes, play the cello, run ultramarathons, and cook gourmet dishes. It's not OK to start a business or to do nonacademic writing (fiction or nonfiction). Again, the main concern being that any significant time dedicated to such activities might have been better spent on conducting research-even though hobbies that are related or unrelated to science both take the same amount of time away from the lab.

Although Carroll's tone is tongue-incheck, his analysis rings true in that research pursuits remain largely perceived as vocational, by both insiders and outsiders. According to this view, the ideal academic worker is devoted solely to the pursuit of knowledge and associated work in the lab, without external interference. It is no longer expected that dedicated scientists are lifelong bachelors - as it was in Newton's and Leibniz's time-or, thankfully, that committed scientists are white males. But deviating too much from the idealized image of the singleminded, focused academic is still considered problematic.

What is the reality now? Do public scientists actually underperform in the lab? Bias against outreach and communication might be reasonable if researchers who communicate to the public do perform worse academically than those who do not. If that is the case, scientists who discourage colleagues from engaging in science communication are doing them a favor, and help them protect their research output. If that is not the case, has contemporary academia overcome the Sagan Effect?

\section{The academic performance of visible scientists: perception versus reality} It remains commonly thought that scientists who perform outreach activities are less successful than those who do not. Consistent with this view, a 2006 Royal Society survey reported an academic concern that public engagement is done by "those who are not good enough for an academic career" (Royal Society, 2006, $\mathrm{p}$ 11). This pervasive belief has been challenged repeatedly, however, by a number of studies set out to quantify the academic performance of scientists who do and do not engage with society. Jensen and colleagues (2008) analyzed extensive data about the outreach, academic production, and career recognition of 3500 scientists at the French National Center for Scientific Research (CNRS). Among the bibliometric indicators of research performance, they considered the total num- 


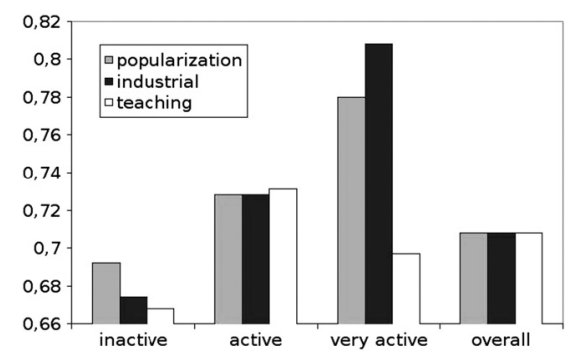

Figure 1. Average $h_{y}$ (h-index divided by career length in years) of inactive, active, and very active scientists in different dissemination activities. Variance tests on the indicators indicated strong significance for popularization activities: $F=6.9, p$ value $=0.01$. From Jensen et al. (2008).

ber of papers that the scientists had published since the beginning of their careers, the average number of publications per year, and the number of citations received (i.e., the Hirsch-, or h-index; Hirsch, 2005). The surprising finding was that scientists who engaged with society were in fact more active academically than the average scientist (Russo, 2010). In other words, dissemination was not done by lesser academics. Rather, wider dissemination activities correlated with higher performance. Conversely, inactivity in popularization efforts was linked to lower performance (Fig. 1). More recently, Bentley and Kyvik (2010) performed a cross-national analysis of popular science writing (i.e., in newspapers and magazines) by university researchers in 13 countries. Consistent with Jensen et al. (2008)'s findings, they found that scientists with popular publications also had higher levels of academic publishing, as well as higher academic rank. The positive relationship between academic and popular writing was consistent across countries and fields of research. Interestingly, there were small but significant discrepancies in the weekly hours worked by academics with and without popular publications. Academics with popular publications worked more hours a week than academics without them ( 49.3 vs $47.8 \mathrm{~h}$ ), but spent fewer hours on the core tasks of teaching, research, and administration (39.0 vs 40.1 h). Bentley and Kyvik (2010) suggested that scientists with popular publications may have more discretion in how they allocate their time. But this does not explain why their academic output is higher despite spending almost $1 \mathrm{~h}$ less a week in core activities than scientists without popular publications.

I have to wonder whether the increased practice in writing (or perhaps more facility with writing) might explain, at least partly, why scientists with popular science articles are also more prolific academic writers (and vice versa). Perhaps scientists who enjoy writing, or have learned to write more prolifically due to their outreach efforts, are able to leverage those skills into higher academic output as well: productive writers are productive writers regardless of genre. In my own personal experience, writing for the public has made me not only a better popular science writer, but a better writer overall. I can now write academic articles faster and better than before I began writing for a general audience. Much of my improvement can be credited to critical feedback from professional editors with whom I have worked on my outreach efforts. Likewise, giving public lectures has improved my academic, institutional, and scientific conference skills.

Ironically, the positive relationship between public visibility and high academic output applied to Carl Sagan himself. Shermer wrote that "Throughout his career, which began in 1957 and ended in December $1996, \ldots$ Sagan averaged a scientific peer-reviewed paper per month" (Shermer, 2002).

\section{To communicate or not: conflicting} messages and academic ambivalence The perception of a Sagan Effect for academics who engage the public is at odds with institutional, professional societies, and funding agency policies that compel scientists to communicate with nonspecialists. The Royal Society in the United Kingdom pointed out that "Researchers need to engage more fully with the public," and France's CNRS stated that two of its six top priorities were "to transfer research results to industries" and "to strengthen the relations between science and society" (Jensen et al., 2008). In the United States, The National Science Foundation scores grant proposals not only on their intellectual merit but also on their "broader impacts" on society: one stated impact is the broad dissemination of research findings to the public (National Science Foundation, 2002).

The ambiguity between the opposite pulling forces of encouragement and discouragement to communicate is apparent in the findings from the Royal Society survey. Whereas most researchers believed that scientists "themselves have a duty, as well as a primary responsibility" to communicate their findings and implications to the lay public, a significant number also felt that science communication was done by substandard researchers (Royal Society, 2006). Jensen et al. (2008) concluded, with some puzzlement, that it remains unknown why "a significant fraction of the scientific community feel that 'only bad scientists' popularize." "Is it a problem of jealousy for colleagues that manage to present their results to a wide audience? Is that because [they believe that] creating knowledge is ... more important than widely disseminating it?" (Jensen et al., 2008).

Rödder (2012) shed some light on the reasons for the academic community's ambivalence toward science communication by pointing out the factors that make dissemination acceptable versus unacceptable. After conducting 55 in-depth interviews with senior and junior researchers from human genome projects in four countries, she found that, for the academic community to deem a scientist's public visibility legitimate, three conditions must be met: (1) sound scientific work (i.e., credible, reputable research); (2) reference to an institutional role (public visibility is expected from the head of an institute, or the president of a major academic association); and (3) no proactive media contact (visibility is appropriate if the scientist was approached by journalists-i.e., the scientist was reluctant to communicate, but did so only because reporters asked him/her-but not so if the scientist initiated contact with the media. Therefore, scientific communities tolerate media interactions or even reward them-if certain conditions are met (Peters, 2013).

Whereas I believe that sound research is fundamental to science communication, I do not think that scientists should speak only as part of their institutional duties, or shy away from contacting the media. Science communication should not be relegated to senior academic administrators and those who would rather not interact with the public. Doing so makes no sense, as it places only those scientists farthest from the bench (the most senior administrative personnel) and the most reluctant to discuss science as our spokespeople. Yet, this unfortunate view could help explain why early career scientists communicate less with the public than those higher up in the academic ladder.

The Royal Society survey found that $86 \%$ of senior scientists were involved in some degree of outreach, versus $14 \%$ of junior scientists (Royal Society, 2006). Likewise, Jensen et al. (2008) found that scientists in higher academic positions were more active disseminators than those in earlier career stages. Jensen et al. 
$\square$ Mostly positive impact

No impact on reputation

Partly positive, partly negative

Don't know

$\square$ Mostly negative impact

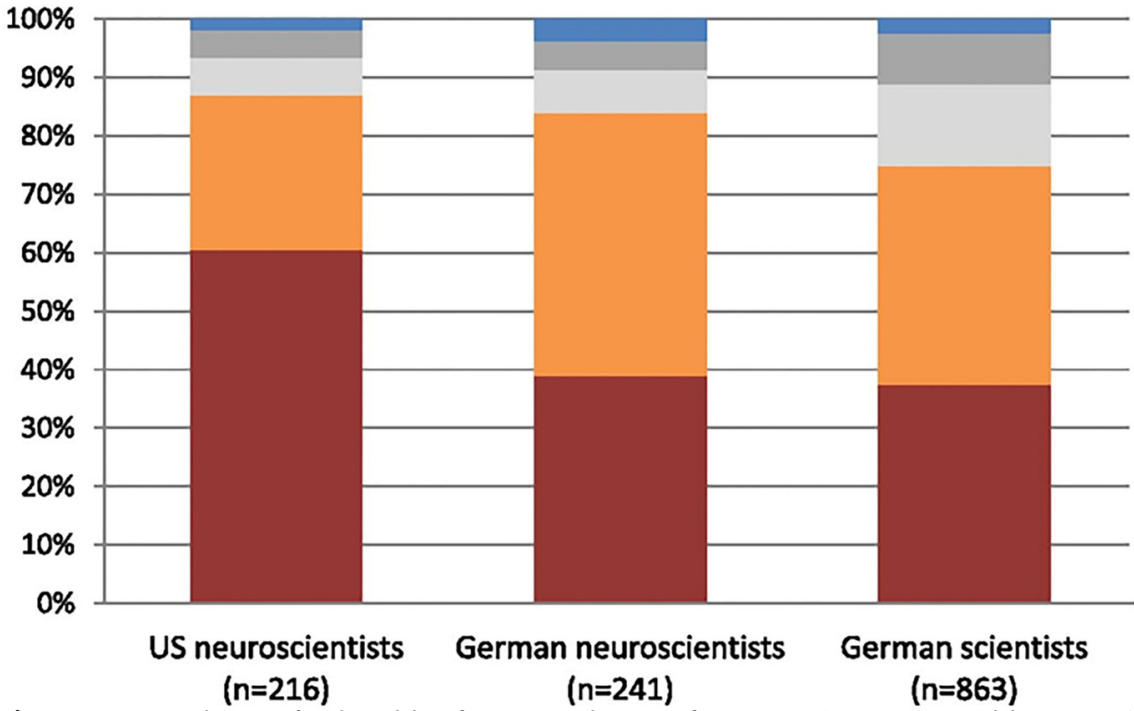

Figure 2. Perceived impact of media visibility of scientists on their scientific reputation. Scientists answered the question: "If the media report on scientists and their research, does this have a positive or negative impact on the scientific reputation among colleagues in your area of research?" From Peters (2013).

(2008) offered that popularization may be largely driven by an external demand (i.e., institutions or journalists) placed upon the scientific elite (especially in the case of prestigious popularization activities, i.e., press, radio and TV interviews, vs websites or lectures at K-12 schools), and moreover reasoned that scientists engaged in dissemination may have specific intellectual or personality characteristics that facilitate such involvement. The Royal Society report moreover proposed that the difference in involvement between senior and junior scientists might be explained by the fact that young investigators "keen to climb the research career ladder [choose to focus] on research and publishing and/or [feel that they need] more experience before they could engage with those outside their research community." One additional reason might be that junior scientists are more strongly discouraged to communicate (i.e., "Wait to write your book until you have tenure") or that they perceive that dissemination activities might put them at a career disadvantage. The Royal Society report advised research institutions to implement "policies which enable a higher proportion of younger scientists to get involved in public engagement" and moreover stated the "need to reward public engagement activity in the career progression of scientists" (Royal Society, 2006). The Society for Neuroscience's Science Education and Outreach Awards (i.e., the Science Education
Award, the Next Generation Award, and the Award for Education in Neuroscience) are commendable steps in this direction, as are a few other science communication prizes awarded by academic and professional associations, but further progress is needed across the board.

It would be tempting to conclude that negative views of dissemination are a thing of the past (the Royal Society survey and the Jensen et al. study are 10 and 8 years old, respectively). Yet, recent analyses indicate that academic attitudes toward-and the practice of-science communication have not changed for the last 30 years (i.e., scientific communities continue to regulate media contacts in ways that compete with encouragement to communicate), despite important technological and social changes during this time period. Thus, a large fraction of contemporary scientists in Germany and the United States perceive media visibility as having both positive and negative career consequences (Fig. 2) (Peters, 2013). David Eagleman, the 2012 recipient of the Society for Neuroscience's Science Educator Award, wrote recently in this journal that outreach activities entail "social risks as well: many scientists admit concern about criticism from colleagues for forays into the public sphere (Eagleman, 2013)."

I have encountered some negativity myself, for instance at the time of my annual performance review at a previous institution. My laboratory had been highly productive in the preceding 12 months, publishing 13 academic (Pubmed-indexed) papers (more than any other science lab in my institute during that period), plus some academic book chapters. In that same time interval, I also published 29 popular science articles (only 9 of them were original; the other 20 were reprinted from previous publications and compiled in a Scientific American special issue). My department chair at the time indicated in my annual evaluation meeting that, whereas my academic productivity had been "stellar," my publication output was unbalanced (in that I had published more popular articles than academic articles). I explained that popular articles may take only 1 or 2 days to write, whereas original research projects often take months (or longer) to complete. He was unconvinced. I left the meeting with the distinct impression that he would have judged my performance more positively, had I neglected to include my popular science articles in my annual progress report altogether.

In a recent reimagining of the Sagan Effect, Neil Hall, a professor of genomics in the United Kingdom, proposed a "Kardashian index," for academics (Hall, 2014a). The metric was to assess the relationship (i.e., discrepancy) between the academic impact and social media impact of scientists. Hall expressed concern that, similar to individuals like Kim Kardashian that are "famous for being famous," certain researchers are "renowned for being renowned," rather than "because of their contributions to the published literature." To illustrate this point, he plotted the number of academic citations against the number of Twitter followers of "a randomish selection of 40 scientists," offering that those with a high $\mathrm{K}$-index "may have built their public profile on shaky foundations.” (Full disclosure: Google Scholar indicates that my papers have been cited 3719 times as of this writing. Because my Twitter followers sum a piteous 95, I have a low K-index-0.158, to be precise, as per Hall's equation-and therefore I am an "undervalued" scientist.) "If your K-index gets above 5," Hall admonishes, "then it's time to get off Twitter and write those papers." Twitter users and science bloggers reacted with predictable outrage, arguing that literature citations are not a measure of scientific rigor, and that the $\mathrm{K}$-index discriminates junior scientists while favoring tenured, well established researchers (Allen, 2014; Curry, 2014; Watson, 2014). Responding to the criticism on Twitter, Hall wrote that he had written his article in jest, while including 
"some semi serious points" (Hall, 2014b). The ambivalence lives on.

\section{The pluses and minuses of science communication on academic careers}

In the personal example above, my communication activities were not merely ignored, but they subtracted from my perceived academic worth. But I have benefitted significantly in my research career from my outreach too, such as by establishing collaborations with colleagues outside of my immediate field and by securing nontraditional funding for various lines of research in my lab. One explicit goal of Jensen et al. (2008) was to find out whether science communication activities help or harm academics, and especially whether scientists that are active in dissemination receive positive institutional recognition in terms of their careers. Their analysis revealed, somewhat surprisingly, that science communication activities are not generally bad for academic careers. On the minus side, they are not very good either: the effects, albeit positive overall, were "generally weak" and "rarely significant.”

Carroll acknowledged that the net impact of science communication on scientists' careers is hard to quantify. In line with Jensen et al. (2008)'s conclusions, he wrote that "It's probably a wash, overall, although the positive or negative aspects could be important in certain individual cases" (Carroll, 2005).

\section{Qualitative survey}

It was with such individual cases in mind that I teamed up with Devin Powell, an experienced reporter and science writer, to interview a selected pool of academics who are also world-renowned neuroscience communicators. I wanted to focus on active, mainstream neuroscientists that engage in the most prestigious forms of science communication (as opposed to academics who conduct dissemination activities that might not be known to their colleagues, such as speaking at elementary schools). Do celebrity disseminators face blow-back over their outreach efforts? To try and answer this question, we came up with a list of active neuroscientists, both junior and senior, that engage the public in ways that should be highly visible to colleagues. We started off with a list of $150+$ names, including TED presenters, writers of popular science blogs and New York Times op-eds, and authors of bestselling books. We then removed winners of Nobel Prize and other major science awards, non-mainstream researchers, and some other special cases. The final list of $80+$ names included some self-described psychologists and other scientists in fields closely related to neuroscience. From these, we obtained approximately a quarter of responses, comprising a mixture of written replies and phone interviews. Consistent with Jensen et al. (2008)'s and Peters (2013)'s findings, qualitative analysis of our sample revealed outright backlash to be the exception rather than the rule. But those few exceptions suggested some troubling trends.

One scientist, who agreed to participate on the condition of anonymity - an indicator of his perceived vulnerability to the Sagan Effect-left his research institute as a junior faculty member because he felt that the institute's director-who had chided him about communicating with the press-was blocking his advancement to associate professor after there had been extensive media coverage of his work. The same researcher, who has published in the highest-impact journals, said that he has been unable to get a grant after further recent media coverage and a giving a related lecture at a TED conference. He has declined an invitation to give a second TED talk in light of the criticism, and will not do further media interviews at present.

The worst for me was the grants. Since this paper [covered extensively in major international media], all my grants got rejected with terrible comments. It was suddenly completely changed. I had 25 grants rejected since the paper in [name of top tier journal]. In this period I had [multiple names of highest impact journals] that came after. Still all my grants are really terribly evaluated .... With comments like the "very well publicized" or the "over-exposed" work of [name of investigator].

Others indicated that their public profile diminished their recognition within their fields.

I'm sure I'll never get into the $\mathrm{Na}$ tional Academy of Sciences despite the fact that my publication record, my citation index, is higher than that of any psychologist in the academy.

[A colleague] has written to the president of the [name of academic association], saying that I am not appropriate for this award. He car- ried on and on and on in this letter to the president, about how [name of investigator] is nothing but a popularizer.

Yet, while many respondents said that they knew backlash existed, they did not believe that their own careers had suffered for it. Indeed, most reported a positive balance. Some asked us for our assurances that this article would indicate that backlash does not happen in every case.

For the most part my colleagues have been particularly supportive and feel that having a scientist write some things about science from the inside helps the public and students to understand it better. It is a worthwhile task that they are generally appreciative of my having undertaken.

It is a complex picture. It could be that, whereas dissemination activities can produce occasional backlash from specific senior colleagues, funding agencies, and even the National Academy of Science, they can also lead to new exciting research lines, collaborations, and funding opportunities that would not have arisen otherwise. Perhaps backlash is underreported in cases where the visible benefits offset the less tangible costs. Indeed, I was surprised when a couple of our respondents stated no experience of backlash. As a scientist in the field, I had heard disparaging comments from other colleagues concerning those specific scientists' outreach-yet those investigators themselves reported no negative opinions from peers.

The book, articles in popular press and TED talk ... helped raise the profile of the research and thus increased the odds of collaborations, academic talk invites, and grants as well as the number of students requesting to work in my lab. In addition, the extra work, thought and literature search I had to do for the outreach projects enhanced my knowledge and triggered new research ideas that ended up in prominent academic journals.

The response within my academic institution has been mixed, from very positive to very negative, and the impact that this has had on my career, funding, and promotion, has been similarly complex.

I think a lot of us don't necessarily feel as though the RO1 system is 
going to be sustainable for us in the future, and that it is something that is going to be able to support us. So, the way my experience has been, that the outreach that we have done, that I have done, has opened a lot of unconventional doors, including source funding, toward funding sources that would not have been available otherwise.

Public visibility confers other advantages too. A 2003 paper found that studies covered by major daily newspapers-but not by network TV-garnered more academic citations than those that did not (Kiernan, 2003). Twitter buzz is less clearly correlated with academic citations, however (Haustein et al., 2014; but see Eysenbach, 2011).

In my own particular case, the benefits have outweighed the costs - but it is only fair to ask why there should be any costs at all. We must also consider the possibility that bias against disseminators may be akin to gender discrimination in that prejudice is rarely stated explicitly, even if acted on-therefore making it difficult to quantify. How do we determine whether implicit bias played a role in a grant rejection, or in the decision to not extend an invitation to speak at a conference? Another factor to keep in mind is the possibility of interaction of various forms of bias: are women and other underrepresented groups at a higher risk of backlash as science communicators? Carroll described female assistant professors who felt that they can only blog using a pseudonym, or else they must stay away from blogging altogether (Carroll, 2008). Minority junior faculty of either gender may feel similar pressures. Yet, these are the specific people whose public visibility would most encourage young underrepresented students into STEM fields. If so, perpetuation of the Sagan Effect not only affects a few academics interested in outreach, but it may have a significant deleterious impact on our society.

Several of our respondents expressed that dissemination is more palatable coming from senior academics who have already achieved renown within their fields than from early-career scientists. If this is the general view, the academic community should strive to correct it. Nobel Prize winners and recipients of other major academic distinctions are outstanding ambassadors of our research. But there is also a place for highly energetic junior academics that have just fallen in love with their disciplines and cannot wait to proclaim their newfound fascination to the world.

If one has received a Nobel Prize, then communication with the public is acceptable, even expected. But when one begins to speak about one's science to the public early in one's career, I think there might well be some punishment from the field. This of course should not be, if the work is solid and the applications are appropriate. But I suspect that it's a price junior people unfortunately have to pay. In my field, even writing a popular book "too early" in one's career is viewed negatively.

University departments, at least in the UK, are now encouraging ... public engagement or outreach ... Having said that, young researchers are often criticized for blogging about their research.

I started when I was already in a tenure-track job, which is a reasonably advanced career stage and already somewhat less at risk of backlash.

I have never had a problem in recent years-but it probably helps if you are well funded by the Wellcome Trust, produce high impact papers and are an FRS . . . but it is complex for young researchers....

\section{Summary and conclusions}

Most scientists agree that science communication is important, and some even say that it is a scientist's duty to interact with the media and the tax-paying public ( $\mathrm{Pe}$ ters, 2013). Yet, the concern remains that science dissemination may be incompatible with a successful academic career, particularly if the scientist is a junior or pretenure investigator. Negative perceptions of dissemination activities are in contrast with institutional statements that such efforts are priorities. The data also indicate that science dissemination is performed by productive and competitive scientists, who receive no career recognition for their outreach efforts. Most disseminators incur no net penalty in their careers - and may even benefit slightlyyet they obtain few or no institutional rewards for their communication activities. Despite the lack of generalized backlash, there is some evidence of severe instantia- tion in individual cases, and certain scientists-especially from underrepresented groups - may be more vulnerable or at a higher risk than others. Jensen et al. (2008) proposed that institutions must find new incentives for dissemination, and the Royal Society has recommended the implementation of "a more effective support system" and "the introduction of significant departmental rewards" (Royal Society, 2006) for those who communicate. These are worthwhile goals, but more pressing perhaps is the need to overcome lingering ambivalence toward engagement in public discourse. I propose that universities enact specific policies to overcome the Sagan Effect at all levelsjust as they have done for decades to weed out bias against underrepresented groups-lest they shoot themselves in the foot. Discovery does not count unless communicated, and we as academics must improve our interactions with the public if we wish to become relevant discussants in society's great debates (Kristof, 2014).

\section{References}

Allen M (2014) We the Kardashians are democratizing science. In: Neuroconscience blog. Available at: http://neuroconscience. com/2014/2008/2001/we-the-kardashiansare-democratizing-science/.

Bentley P, Kyvik S (2010) Academic staff and public communication: a survey of popular science publishing across 13 countries. Public Understanding of Science:0963662510384 461.

Carroll S (2005) It's not the blog [personal blog]. Available at: http://blogs.discovermagazine.com/cosmicvariance/2005/2010/2011/ its-not-the-blog/\#.VpAgf_krIuZ.

Carroll S (2008) Bloggingg without tenure [personal blog]. Available at: http://www.preposterousuniverse.com/blog/2008/2002/2020/ blogging-without-tenure.

Carroll S (2011) How to get tenure at a major research university [personal blog]. Available at: http://www.preposterousuniverse.com/ blog/ 2011/2003/2030/how-to-get-tenure-ata-major-research-university/.

Curry J (2014) Kardashian index. In: Climate Etc. blog. Available at: http://judith curry. com/2014/2008/2003/kardashian- index/.

Davidson K (1999) Carl Sagan: a life. New York: Wiley.

Eagleman DM (2013) Why public dissemination of science matters: a manifesto. J Neurosci 33:12147-12149. CrossRef Medline

Eysenbach G (2011) Can tweets predict citations? Metrics of social impact based on Twitter and correlation with traditional metrics of scientific impact. J Med Internet Res 13:e123. CrossRef Medline

Hall N (2014a) The Kardashian index: a measure of discrepant social media profile for scientists. Genome Biol 15:424. CrossRef Medline

Hall N (2014b) Available at: https://twitter.com/ neilhall_uk/status/494405938133348352. 
Haustein S, Peters I, Sugimoto CR, Thelwall M, Larivière V (2014) Tweeting biomedicine: an analysis of tweets and citations in the biomedical literature. J Assoc Info Sci Technol 65:656-669. CrossRef

Hirsch JE (2005) An index to quantify an individual's scientific research output. Proc Natl Acad Sci U S A 102:16569-16572. CrossRef Medline

Jensen P, Rouquier JB, Kreimer P, Croissant Y (2008) Scientists who engage with society perform better academically. Sci Public Policy 35:527-541. CrossRef

Kiernan V (2003) Diffusion of news about research. Sci Commun 25:3-13. CrossRef

Kristof T (2014) Professors, we need you! New York Times, February 16, 2014.
Morrison D (2006) Carl Sagan: the people's astronomer. AmeriQuests 3.

National Science Foundation (2002) Merit review broader impacts criterion: representative activities. Available at: http://www.nsf.gov/ pubs/2002/nsf022/bicexamples.pdf.

Peters HP (2013) Gap between science and media revisited: scientists as public communicators. Proc Natl Acad Sci U S A 110[Suppl 3]:14102-14109. CrossRef Medline

Poundstone W, Chyba C (1999) Carl Sagan: a life in the cosmos. New York: Henry Holt.

Rödder S (2012) The ambivalence of visible scientists. In: The sciences' media connectionpublic communication and its repercussions, pp 155-177. Heidelberg: Springer.

Royal Society (2006) Factors affecting science communication: a survey of scientists and engineers, 2006. London: The Royal Society.

Russo G (2010) Outreach: meet the press. Nature 468:465-467. CrossRef

Shermer M (1999) The measure of a life: Carl Sagan and the science of biography. Skeptic 17:32-39.

Shermer MB (2002) The view of science Stephen Jay Gould as historian of science and scientific historian, popular scientist and scientific popularizer. Soc Stud Sci 32:489-524. CrossRef Medline

Watson M (2014) Citations are not a measure of quality. In: Opiniomics blog. Available at: https://biomickwatson.wordpress.com/2014/ 2007/2030/citations-are-not-a-measure-ofquality/. 